\title{
A Study on the Applicability of Corrosion Inhibitor for Outdoor Copper Alloy
}

\author{
Jeong Ah Shin I Koang Chul Wi, \\ Cultural Heritage Center, Ulsan Development Institute, Ulsan, 44720, Korea \\ *Department of Cultural Heritage Conservation, Hanseo University, Seosan, 31962, Korea \\ ${ }^{1}$ Corresponding Author: kcwi@hanseo.ac.kr, +82-41-660-1043
}

\begin{abstract}
Outdoor copper alloy is exposed to the atmospheric environment, accelerating corrosion progress compared with indoor copper alloy. In order to prevent corrosion, the outdoor copper alloy is coated with wax to block external corrosion factors. However, corrosion of the inside of the coating film is highly likely to continue without the internal corrosion prevention treatment. B.T.A, which is used as a copper alloy water-soluble corrosion inhibitor, has a high possibility of being harmful to the human body and is mainly used to treat excavated artifacts. This study had selected the water-soluble corrosion inhibitor, which was easier to use than the existing wax and B.T.A being used in corrosion inhibition treatment for outdoor copper alloy. A comparative study was conducted on B.T.A, which is a water-soluble corrosion inhibitor used on excavated artifacts, and $\mathrm{VCI}^{\circledR}$, Rus $^{\circledR}$, and L-cys, an amino acid corrosion inhibitor, used for tin bronze test pieces. The experimental method was conducted for a certain period of time with the salt, acid, and air pollution affecting the corrosion of outdoor copper alloy. Based on experiment results, it was concluded that the best water - soluble copper alloy corrosion inhibitor in the atmospheric environment is $\mathrm{VCI}^{\mathbb{R}}$. and it could be considered to be applied in replacement of B.T.A due to its low harmfulness. In addition, $\mathrm{VCI}^{\circledR}$ is judged to serve as a corrosion inhibitor for outdoor copper alloy because it showed the best result even in the outdoor exposure test which is a real atmospheric environment.
\end{abstract}

Key Words: VCI, Corrosion inhibitor, Outdoor copper alloy, Outdoor environment

\section{INTRODUCTION}

Copper alloy could be worked into any desired shape through smelting and refining processes, but after being worked, it is unstable and tends to return to a stable condition that is a natural mineral's original form. This process is called corrosion, which progresses as metal ions and physical, biological and chemical corrosion factors repeat combination and dissociation to form oxides.

Corrosion factors are most affected by environmental factors such as oxygen, salt ions, moisture, ultraviolet rays, temperature and microorganisms, and they occur in combination rather than acting separately to produce corrosions when chemical reactions occur(Seo, 2008). Because the copper alloy, in which corrosion is produced, loses its original shape to show distorted images and the change of color and luster etc., anti-corrosion treatment is carried out to remove corrosion factors or prevent from producing corrosions.

Outdoor copper alloy is exposed to noxious gas, acid rain, acid fog, salt and dust etc. caused by pollution of atmospheric environment to be corroded more rapidly than indoor copper alloy to cause damages, so anti-corrosion treatment preventing re-corrosion by quickly treating corrosion factors is important for large copper alloy exposed to the outdoors. Anti-corrosion treatment is a method that is applied primarily to copper alloy, which blocks external corrosion factors to minimize the pace of corrosion. Small-sized copper alloy allows of impregnation, but for large copper alloy such as outdoor sculptures, coating and spray treatment is carried out because it is so bulky that impregnation is not possible.

Due to such an anti-corrosion treatment method, anti-corrosion treatment for outdoor copper alloy blocks 
external corrosion factors by coating wax but internal anti-corrosion treatment is excluded, and because Benzotriazole(B.T.A) being used as the existing corrosion inhibitor for copper alloy is harmful to human bodies and limited to treatment for excavated relics, anti-corrosion treatment is not carried out for outdoor copper alloy in reality.

Accordingly, to apply easy-to-use water-soluble corrosion inhibitors during anti-corrosion treatment for outdoor copper alloy, a study was conducted to compare and analyze B.T.A, which is the existing water-soluble corrosion inhibitor for copper alloy, and industrial water-soluble corrosion inhibitors for copper alloy to determine whether or not to substitute the wax being used in the existing anti-corrosion treatment for outdoor copper alloy. For corrosion inhibitors, It would like to select a kind of B.T.A. which is the existing water-soluble corrosion inhibitor, two kinds of industrial water-soluble corrosion inhibitors for copper alloy, and a kind of echo-friendly amino acid series corrosion inhibitor to apply them to test pieces of tin-bronze which is the main material of outdoor copper alloy to verify the corrosion inhibition effect of blocking atmospheric pollutants through environmental experiments and material property measurements, and provide applicability of actual preservation treatment for outdoor copper alloy sculptures.

\section{MATERIALS AND METHODS}

\subsection{Materials}

To study by comparing with B.T.A which is the existing water-soluble corrosion inhibitor for copper alloy among industrial water-soluble corrosion inhibitors for copper alloy that are easy to apply to outdoor copper alloy, it was selected a transparent product with no effect on the exterior such as decolorization and color development after preservation treatment, which is a water-soluble corrosion inhibitor being easy to remove later. Accordingly, it was selected Volatile Corrosion Inhibitor ${ }^{\circledR}(\mathrm{VCI})($ Chun et al., 1999) which is an industrial water-soluble corrosion inhibitor for copper alloy, Rustyno-NFM ${ }^{\circledR}$ (Rus) which is a silicate series corrosion inhibitor and a rust-proof agent product of Handong Technique Chemical Corp., and L-Cysteine(L-cys) which is an echo-friendly amino acid series and presented as a very effective corrosion inhibitor (Woo, 2013). B.T.A is the most commonly used watersoluble corrosion inhibitor, $3 \mathrm{wt} \%$ (in alcohol) was used for B.T.A, $100 \mathrm{wt} \%$ was used for VCI and Rus, and 10 $\mathrm{mM}$ (in distilled water) was used for L-cys(Table 1).

\subsection{Test piece}

The test piece was made by cutting tin-bronze $(\mathrm{Cu} 92 \%$ $+\mathrm{Sn} 8 \%$ ), which is an alloy of copper and tin and widely used for materials of outdoor copper alloy sculptures(Kwon et al., 2017), into $50 \mathrm{~mm} \times 50 \mathrm{~mm} \times 2 \mathrm{~mm}$ to grind with sand papers in order of $\# 400, \# 600, \# 800$ and $\# 1000$. After grinding the test piece, it was immersed into acetone to clean with a ultrasonic cleaner for 5 minutes to remove fluid films, and dry it with a hot-air $\operatorname{dryer}\left(70^{\circ} \mathrm{C}\right)$ for 12 hours to remove internal moisture. After drying, it was immersed in the corrosion inhibitor to depressurize to $20 \mathrm{mmHg}$, impregnated at normal pressure for 1 hour after 2-hour vacuum impregnation in a vacuum, and after impregnation, natural drying was carried out for 12 hours.

Table 1. Corrosion inhibitor types and characteristics

\begin{tabular}{ccc}
\hline Corrosion inhibitor & Concentrations & Characteristics \\
\hline B.T.A & B.T.A $3 \mathrm{wt} \%$ (in alcohol) & Copper alloy corrosion inhibitor \\
\hline VCI & VCI $100 \mathrm{wt} \%$ & Volatile corrosion inhibitor \\
\hline Rus & Rus $100 \mathrm{wt} \%$ & Coating corrosion inhibitor \\
\hline L-cys & L-cys $10 \mathrm{mM} \mathrm{(in} \mathrm{distilled} \mathrm{water)}$ & Amino acid corrosion inhibitor \\
\hline
\end{tabular}




\subsection{Methods}

The experiment was conducted by dividing into environmental experiments and measurement methods, and for environmental experiments, it would like to compare the weather resistance of corrosion inhibitors when exposed to outdoor environments by conducting salt spray, acid corrosion and outdoor exposure tests. For the measurement method, it would like to observe its surface and measure chromaticity, gloss, corrosion rate and contact angle as the material property analysis method to check whether or not the corrosion inhibitor is resistant to moisture and analyze the harmfulness and risk of corrosion inhibitors based on the gas chromatographic (GC) analysis as a scientific analysis method and the MSDS data.

\subsubsection{Environmental experiments}

For environmental experiments, it was conducted three different tests such as salt spray, acid corrosion and outdoor exposure ones. In the salt spray test, the salt spray tester(Q-lab Corporation, CRH-1100, USA) was used in accordance with KS D 9520, and it was exposed to a $\mathrm{NaCl}$ solution of $\mathrm{pH} 6.5 \sim 7.2$ and $5 \mathrm{wt} \%$ in the condition of the relative humidity $95 \sim 98 \%, 35 \pm 2^{\circ} \mathrm{C}$ for 48 hours to finish when observing corrosion products.

In the acid corrosion test, the test piece dried after immersing in the corrosion inhibitor was immersed in the $1 \mathrm{wt} \%$ sulfuric acid $\left(\mathrm{H}_{2} \mathrm{SO}_{4}\right)$ solution dissolved in $99 \mathrm{wt} \%$ distilled water for 10 minutes, and then was dried. To accelerate corrosion, after immersing the desiccator, in which the test piece was put in, into the constant-temperature water bath being set in a hot and humid environment $\left(50 \pm 2{ }^{\circ} \mathrm{C}, 90 \pm 5 \%\right)$ and sealed, it was exposed for 8 hours, and left in the room where maintained constant environment $\left(20 \pm 2^{\circ} \mathrm{C}, 20 \pm 5 \%\right)$ for 16 hours(Kim, 2012). After repeating such a process for 72 hours to corrode again to finish the experiment, it would like to measure the weight before and after exposure to apply the weight reduction method to determine the corrosion rate.

In the outdoor exposure test, the frame was made of wood that did not affect when being in contact with the copper alloy test piece, the test piece perforated at the top and bottom was fixed with fishing lines, then it was situated at a shadowless sunny place facing the south with a grade of $\measuredangle 30^{\circ}$ to conduct the experiment for 720 hours to be exposed uniformly, and the corrosion aspect was observed at an interval of 360 hours.

\subsubsection{Measurement}

For the measurement, it was conducted two different methods such as material property analysis and scientific analysis ones. In the material property analysis method, the color and form of the stuck rust was observed with the naked eye or through a digital microscope(DFC295, Leica Co., Japan) to measure changes of the test piece before and after the environmental experiment. In the chromaticity measurement, the values of $\mathrm{L}^{*}, \mathrm{a}^{*}, \mathrm{~b}^{*}$ and $\Delta$ $E^{*} a b$ were recorded to compare overall changes of chromaticity by measuring with a spectrum colorimeter (CHROMA METER CM-A145, MINOLTA Co., Japan). After measuring five times for each test piece, the mean value was calculated to use three measured values except the maximum and minimum ones. For the surface gloss, after measuring five times for each test piece with a glossmeter(Gloss Checker IG-320, HORIBA Co., Japan), the mean value was calculated by using three measured values except the maximum and minimum ones.

For the method to measure the corrosion level of the corroded test piece, the weight reduction measurement method by the immersion corrosion was used in accordance with the ASTM G 31 Immersion Corrosion method, and for the method to calculate the corrosion rate, after the immersion corrosion test in conformity with the public notice time, it was washed with the distilled water to remove chemicals attached to the surface, and after using physical and chemical methods to remove corrosion products attached to the surface of test piece, the weight after drying was measured. The corrosion rate was represented as the thickness reduction rate for a certain period of time by calculating the weight reduced per unit area and per unit time in accordance with the following equation. The corrosion rate shown in $\mathrm{mm} / \mathrm{yr}$ was represented as the equation below, and it was 
Table 2. Ralative corrosion resistance

\begin{tabular}{cccc}
\hline Ralative corrosion resistance & $\mathrm{mpy}$ & $\mathrm{mm} / \mathrm{yr}$ & $<\mathrm{m} / \mathrm{yr}$ \\
\hline Outstanding & $<1$ & $<0.02$ & $<25$ \\
\hline Excellent & $1 \sim 5$ & $0.02 \sim 00.1$ & $25 \sim 100$ \\
\hline Good & $5 \sim 20$ & $0.1 \sim 0.5$ & $100 \sim 500$ \\
\hline Fair & $20 \sim 50$ & $0.5 \sim 1$ & $500 \sim 1000$ \\
\hline Poor & $50 \sim 200$ & $1 \sim 5$ & $1000 \sim 5000$ \\
\hline Unacceptable & $200<$ & $5<$ & $5000<$ \\
\hline
\end{tabular}

compared the corrosion rate values calculated by measuring the weight loss(Fontana, 1986)(Table 2).

$$
\mathrm{mm} / \mathrm{yr}=\frac{87.6 \mathrm{w}}{\text { DAT }}
$$

W : Weight loss (mg), D : Density $\left(\mathrm{g} / \mathrm{cm}^{3}\right)$,

A : Apparent $\left(\mathrm{cm}^{2}\right), \mathrm{T}:$ Time $(\mathrm{h})$

The resistance to moisture was checked by measuring the contact angle, and it was determined that a nearhydrophobic film was formed to have a higher effect of corrosion inhibition as the film's contact angle of the corrosion inhibitor created on the test piece was measured greater (Kim, 2010).

The GC analysis was conducted for the scientific analysis method. For the B.T.A which is a water-soluble corrosion inhibitor for copper alloy, its use is currently limited because the carcinogen possibility for the contained benzene is presented through the research findings. However, since there is no suitable substitute, this study would like to verify the chemical structure of corrosion inhibitors through the gas chromatography mass spectrometry to present the less harmful watersoluble corrosion inhibitor as a substitute of B.T.A. Based on the result after analyzing, it would like to compare harmfulness of the water-soluble corrosion inhibitors through the material safety data sheet(MSDS) data of the Korea Occupational Safety and Health Agency.

\section{RESULTS}

\subsection{Environmental experiments}

As a result of measuring the chromaticity change values
Table 3. Microscope observations of salt water spray exposure $(\times 0.75)$

\begin{tabular}{lll}
\hline $\begin{array}{c}\text { Corrosion } \\
\text { inhibitor }\end{array}$ & $\begin{array}{c}\text { After surface } \\
\text { treatment }\end{array}$ & $\begin{array}{c}\text { Exposure after } 48 \\
\text { hours }\end{array}$ \\
\hline B.T.A & & \\
\hline VCI & & \\
\hline Rus & & \\
\hline
\end{tabular}

before and after corrosion inhibitor treatment, it could be verified that $\mathrm{VCI}^{\circledR}$ made surface color differences before and after treatment because its $\mathrm{L}^{*}$ value was a black series which indicated the darkened change values. In particular, it could be verified that L-cys changed its color to red series as its amino acid constituent combined with $\mathrm{Cu}$. For the $\Delta \mathrm{E}^{*} \mathrm{ab}$ change values which could 
Table 4. Color-difference result of salt water spray exposure

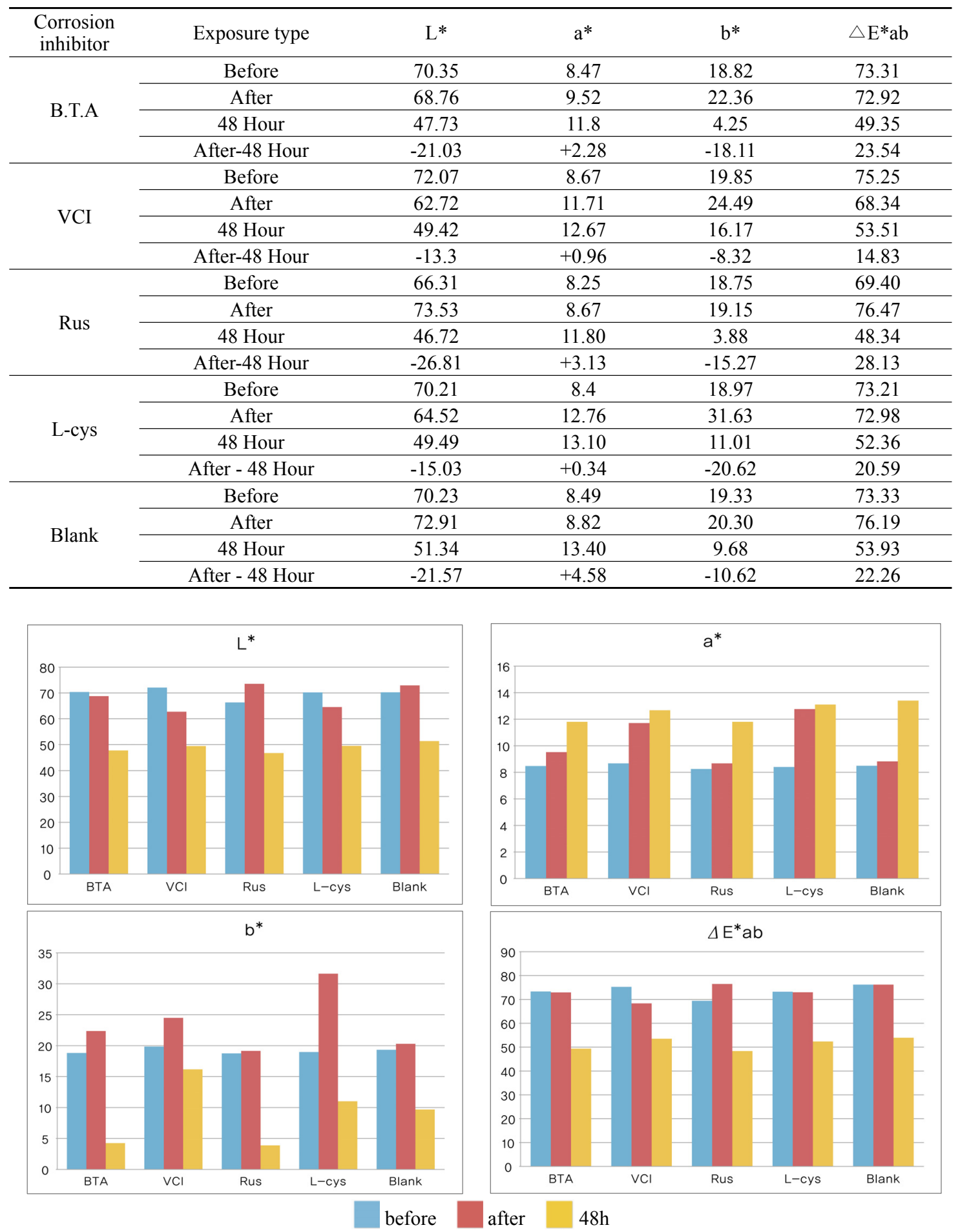

Figure 1. Color-difference value of salt water spray exposure. 
Table 5. Gloss measurement of Salt water spray exposure

\begin{tabular}{cccccc}
\hline \multirow{2}{*}{ Exposure type } & \multicolumn{5}{c}{ Corrosion inhibitor } \\
\cline { 2 - 6 } & B.T.A & VCI & Rus & L-cys & Blank \\
\hline Before & 147.3 & 170.2 & 181.8 & 152.2 & 186.2 \\
\hline After & 146 & 85.3 & 125 & 127.3 & 186.2 \\
\hline 48 Hour & 7.0 & 18.3 & 14.3 & 15.1 & 46.5 \\
\hline After-48 Hour & -139 & -67.0 & -110.7 & -112.2 & -139.7 \\
\hline
\end{tabular}

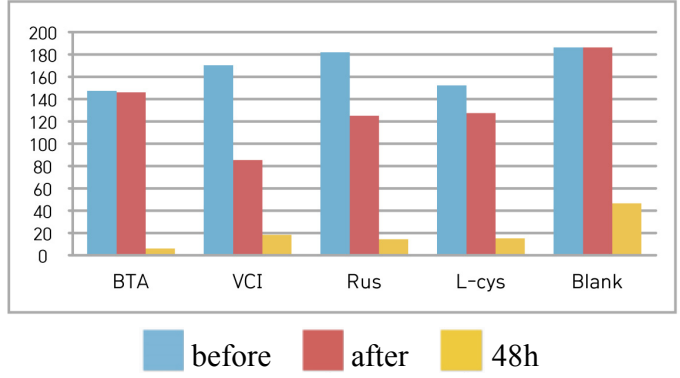

Figure 2. Gloss measurement of salt water spray exposure.

identify overall color changes, the water-soluble corrosion inhibitor VCI showed the greatest change value and the amino acid series L-cys showed the smallest change values(Table 4).

As a result of measuring the gloss before and after corrosion inhibitor treatment, it could be verified that the gloss decreased on the whole. Before and after applying corrosion inhibitors, while B.T.A ${ }^{\circledR}$ showed the smallest change values $(1.3 \sim 32.7), \mathrm{VCI}^{\circledR}$ showed the greatest change values( $84.9 \sim 107.6)$, so it could be verified that B.T.A is the most stable in the gloss.

On the whole, as a result of salt spray, acid corrosion and outdoor exposure tests, it could be verified that $\mathrm{VCI}^{\circledR}$ showed the greatest change values in the color change and gloss, while L-cys showed the least change values.

\subsubsection{Salt spray exposure test}

As a result of the salt spray test, reddish brown rust was stuck over all, stains in which corrosion inhibitor run by salt water was observed in all the test pieces except Blank in which corrosion inhibitor was not applied, so it could be verified that the corrosion inhibitor was watersoluble that dissolves in water. Based on overall color changes and the produced corrosion compounds when observing through microscopes, it could be verified that the change of VCI was the smallest(Table 3 ).

Table 4 shows the chromaticity values after being exposed to the salt water environment for 48 hours. The corrosion inhibitor with the greatest change of $L^{*}$ values was Rus, which showed -26.81, and the corrosion inhibitor with the smallest change while becoming dark into black series was VCI, which showed -13.3. For the $\Delta$ $E^{*}$ ab change values, Rus was 28.13, which color difference was greatly changed, and VCI was 14.83, which showed the smallest color difference, so it could be verified that the color change was stable in the salt water environment. Overall change of the color difference was in the order of Rus $>$ B.T.A $>$ Blank $>$ L-cys $>$ VCI, and all the values were above 20 except VCI, which showed that the change of color difference was great(Figure 1).

Table 5 shows the gloss values after being exposed to the salt water environment for 48 hours. Comparing the gloss values after being exposed to the salt water environment for 48 hours, Blank was -139.7 , which was the biggest change, and VCI was -67.0 , which could obtain the smallest change. It was verified that the gloss change became bigger in the order of Blank $>$ B.T.A $>$ L-cys $>$ Rus $>$ VCI, and it could be known that VCI had superior effects of corrosion inhibition in the salt water environment (Figure 2). When comparing overall chromaticity and gloss values, Rus showed the greatest change of the chromaticity values, while VCI showed the smallest change among the test pieces treated by corrosion inhibitors, so it could be verified that VCI has better effects of corrosion inhibition in the salt water environment. 


\subsubsection{Acid corrosion exposure test}

As a result of the acid corrosion test, corrosion products were observed on the surface except VCI and L-cys. On the basis of overall color changes and the produced corrosion compounds when observing through microscopes, it could be verified that the corrosion inhibition effect of VCI was the best(Table 6).

Table 7 shows the chromaticity values after being exposed to the acid corrosion environment for 72 hours. The corrosion inhibitor having the greatest change of $\mathrm{L}^{*}$ values after being exposed to acid corrosion for 72 hours was Rus, which showed -22.51 and became dark into black series. On the contrary, the corrosion inhibitor with the smallest change was VCI, which showed -11.55 . For the $\Delta \mathrm{E}^{*}$ ab change values, Rus was 22.28 , which showed a great change of color difference, and VCI was 12.34, which showed the smallest color difference. Overall change of the color difference was in the order of Rus $>$ Blank $>$ L-cys $>$ B.T.A $>$ VCI, and it could be verified there were color changes(Figure 3 ).
Table 6. Microscope observations of acid environment exposure $(\times 2.5)$

\begin{tabular}{ccc}
\hline $\begin{array}{c}\text { Corrosion } \\
\text { inhibitor }\end{array}$ & $\begin{array}{c}\text { After surface } \\
\text { treatment }\end{array}$ & $\begin{array}{c}\text { Exposure after } \\
72 \text { hours }\end{array}$ \\
\hline B.T.A & & \\
\hline VCI & & \\
\hline Rus & & \\
\hline L-cys & & \\
\hline
\end{tabular}

Table 7. Color-difference result of acid environment exposure

\begin{tabular}{|c|c|c|c|c|c|}
\hline $\begin{array}{l}\text { Corrosion } \\
\text { inhibitor }\end{array}$ & Exposure type & $\mathrm{L}^{*}$ & $a^{*}$ & $b^{*}$ & $\triangle \mathrm{E}^{*} \mathrm{ab}$ \\
\hline \multirow{4}{*}{ B.T.A } & Before & 71.38 & 8.34 & 18.73 & 74.26 \\
\hline & After & 67.42 & 9.39 & 21.77 & 71.46 \\
\hline & 72 Hour & 50.49 & 5.68 & 16.11 & 53.30 \\
\hline & After-72 Hour & -16.93 & -3.71 & -5.66 & 18.16 \\
\hline \multirow{4}{*}{ VCI } & Before & 74.79 & 8.59 & 20.05 & 77.90 \\
\hline & After & 66.76 & 11.72 & 24.5 & 72.07 \\
\hline & 72 Hour & 55.21 & 9.54 & 20.72 & 59.73 \\
\hline & After-72 Hour & -11.55 & -2.18 & -3.78 & 12.34 \\
\hline \multirow{4}{*}{ Rus } & Before & 66.09 & 8.34 & 18.67 & 69.18 \\
\hline & After & 75.30 & 8.65 & 19.02 & 78.14 \\
\hline & 72 Hour & 52.79 & 6.31 & 17.15 & 55.86 \\
\hline & After-72 Hour & -22.51 & -2.34 & -1.87 & 22.28 \\
\hline \multirow{4}{*}{ L-cys } & Before & 70.73 & 8.36 & 18.87 & 73.67 \\
\hline & After & 64.66 & 12.74 & 31.66 & 73.11 \\
\hline & 72 Hour & 51.95 & 3.62 & 17.48 & 54.93 \\
\hline & After-72 Hour & -12.71 & -9.12 & -14.18 & 18.18 \\
\hline \multirow{4}{*}{ Blank } & Before & 70.26 & 8.74 & 19.56 & 73.45 \\
\hline & After & 72.90 & 8.76 & 19.33 & 75.92 \\
\hline & 72 Hour & 52.53 & 4.80 & 16.59 & 55.29 \\
\hline & After-72 Hour & -20.37 & -9.16 & -2.74 & 20.63 \\
\hline
\end{tabular}



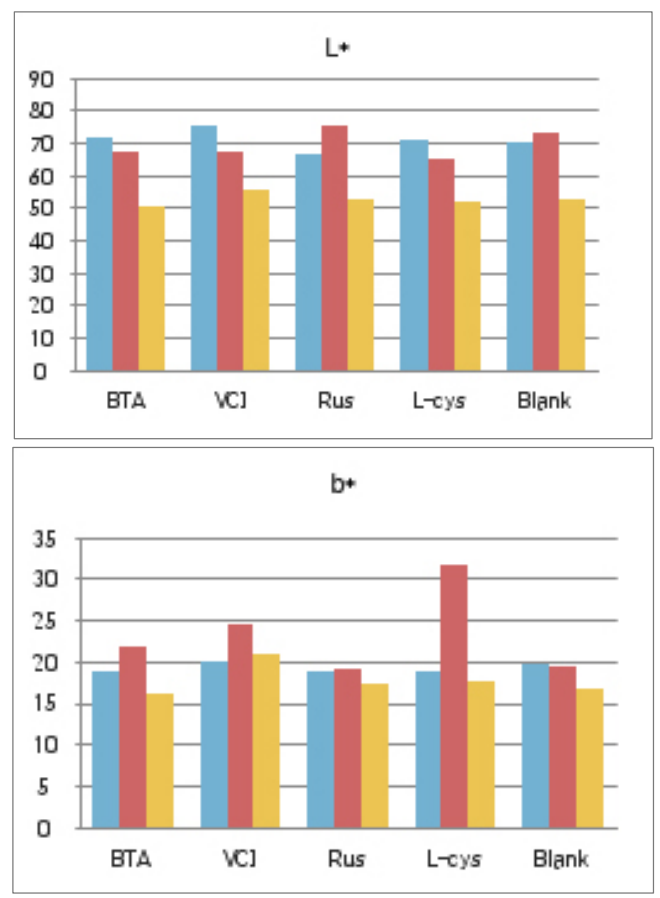

before
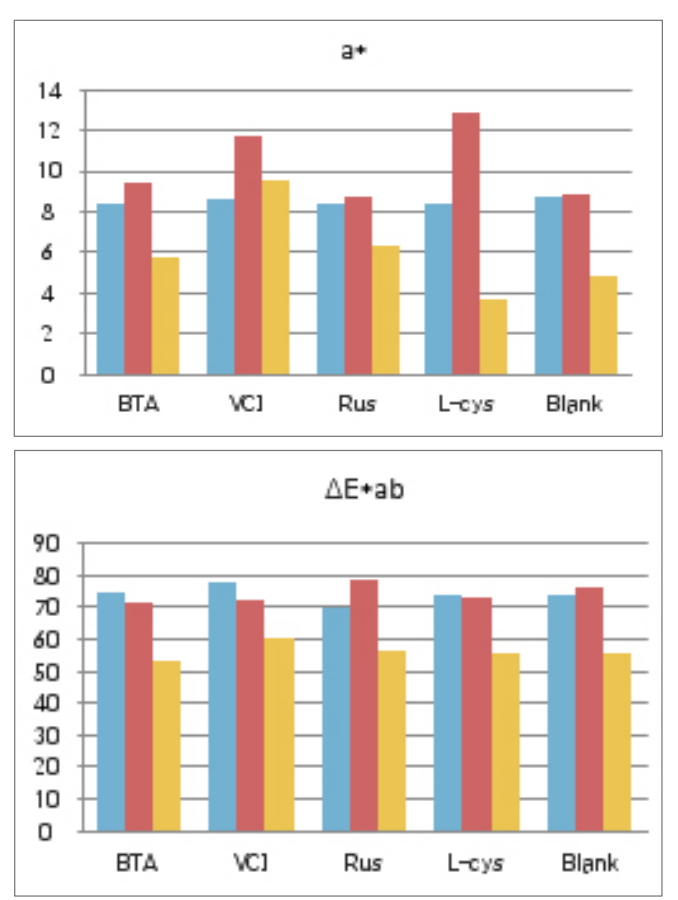

after

$72 \mathrm{~h}$

Figure 3. Color-difference value of acid environment exposure.

Table 8. Gloss measurement of acid environment exposure

\begin{tabular}{cccccc}
\hline \multirow{2}{*}{ Exposure type } & \multicolumn{5}{c}{ Corrosion inhibitor } \\
\cline { 2 - 6 } & B.T.A & VCI & Rus & L-cys & Blank \\
\hline Before & 160.4 & 179.1 & 165.4 & 154 & 157 \\
\hline After & 145.2 & 71.5 & 135.4 & 133.1 & 156.3 \\
\hline 72 Hour & 113.4 & 105 & 120.2 & 108.3 & 83 \\
\hline After-72 Hour & -31.8 & +33.5 & -15.2 & -24.8 & -73.3 \\
\hline
\end{tabular}

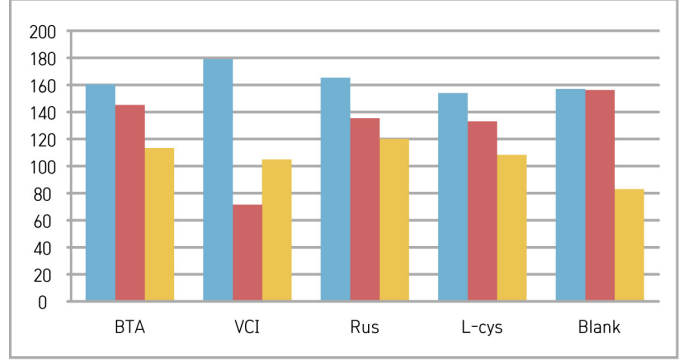

before after $72 \mathrm{~h}$

Figure 4. Gloss measurement of acid environment exposure.
Table 8 shows the gloss values after being exposed to the acid corrosion test for 72 hours. Comparing the gloss values after being exposed to the acid corrosion test for 72 hours, Blank was -73.3 , which decreased the most greatly, and $\mathrm{VCI}$ was +33.5 , which showed the increased change value, so it was considered to form a film in the acid corrosion environment(Figure 4).

It was verified that the gloss change became bigger in the order of Blank $>$ B.T.A $>$ L-cys $>$ Rus $>$ VCI, and it could be known that VCI had superior effects of corrosion inhibition in the acid environment. 
Table 9. Weight of acid environment exposure

\begin{tabular}{ccccc}
\hline Corrosion inhibitor & Before & 72 Hours exposure & After & Decrease variation (\%) \\
\hline B.T.A & 33.608 & 33.400 & 0.208 & 0.000301 \\
\hline VCI & 33.786 & 33.766 & 0.020 & 0.000028 \\
\hline Rus & 33.860 & 33.828 & 0.032 & 0.000045 \\
\hline L-cys & 33.855 & 33.841 & 0.014 & 0.000020 \\
\hline Blank & 33.606 & 33.477 & 0.129 & 0.000186 \\
\hline
\end{tabular}

When comparing overall chromaticity values, Rus showed the greatest change, while VCI showed the smallest change, so it could be verified that VCI has superior effects of corrosion inhibition in the acid environment. For the gloss values, the change values of other test pieces decreased, while the change value of VCI increased, so it was considered to form a film in the acid environment, but it was considered to be able to have an effect on the change of surface gloss.

For the result of measuring the acid corrosion rate, B.T.A was $0.000301 \%$, the highest decrement, which was considered to be vulnerable to the acid corrosion environment, while L-cys was $0.000028 \%$, the lowest decrement, so it was considered to have a better corrosion inhibition effect(Table 9).

\subsubsection{Outdoor exposure test}

As a result of the outdoor exposure test, corrosion compounds were observed on the whole, and it could be verified even with the naked eye that L-cys was greatly corroded. On the contrary, it could be verified that VCI was stable in the outdoor atmospheric environment because metal surface gloss was observed. Based on overall color changes and the produced corrosion compound when observing through a microscope, it was verified that VCI had superior corrosion inhibition effects because the least corrosion compound was observed(Table 10).

Table 11 shows the chromaticity values after being exposed to the outdoor environment for 720 hours. For the $\Delta \mathrm{E}^{*} \mathrm{ab}$ change values after being exposed for 720 hours, Blank was 20.55, which showed a great change of color difference, and VCI was 14.25, which showed the smallest color difference. Overall changes of color
Table 10. Microscope observations of outdoor environment exposure $(\times 0.75)$

\begin{tabular}{|c|c|c|}
\hline $\begin{array}{c}\text { Corrosion } \\
\text { inhibitor }\end{array}$ & $\begin{array}{c}\text { After surface } \\
\text { treatment }\end{array}$ & $\begin{array}{c}\text { Exposure after } 720 \\
\text { hours }\end{array}$ \\
\hline B.T.A & & \\
\hline VCI & & \\
\hline Rus & & \\
\hline L-cys & & \\
\hline Blank & & \\
\hline
\end{tabular}

difference were in the order of Blank $>$ L-cys $>$ Rus $>$ B.T.A > VCI, and only the Blank excluded from corrosion inhibition treatment was above 20, which change value was great, so it could be verified that it had an effect of corrosion inhibition treatment(Figure 5).

Table 12 shows the gloss values after being exposed to the outdoor environment for 720 hours. Comparing the gloss values after being exposed to the outdoor 
Table 11. Color-difference result of outdoor environment exposure

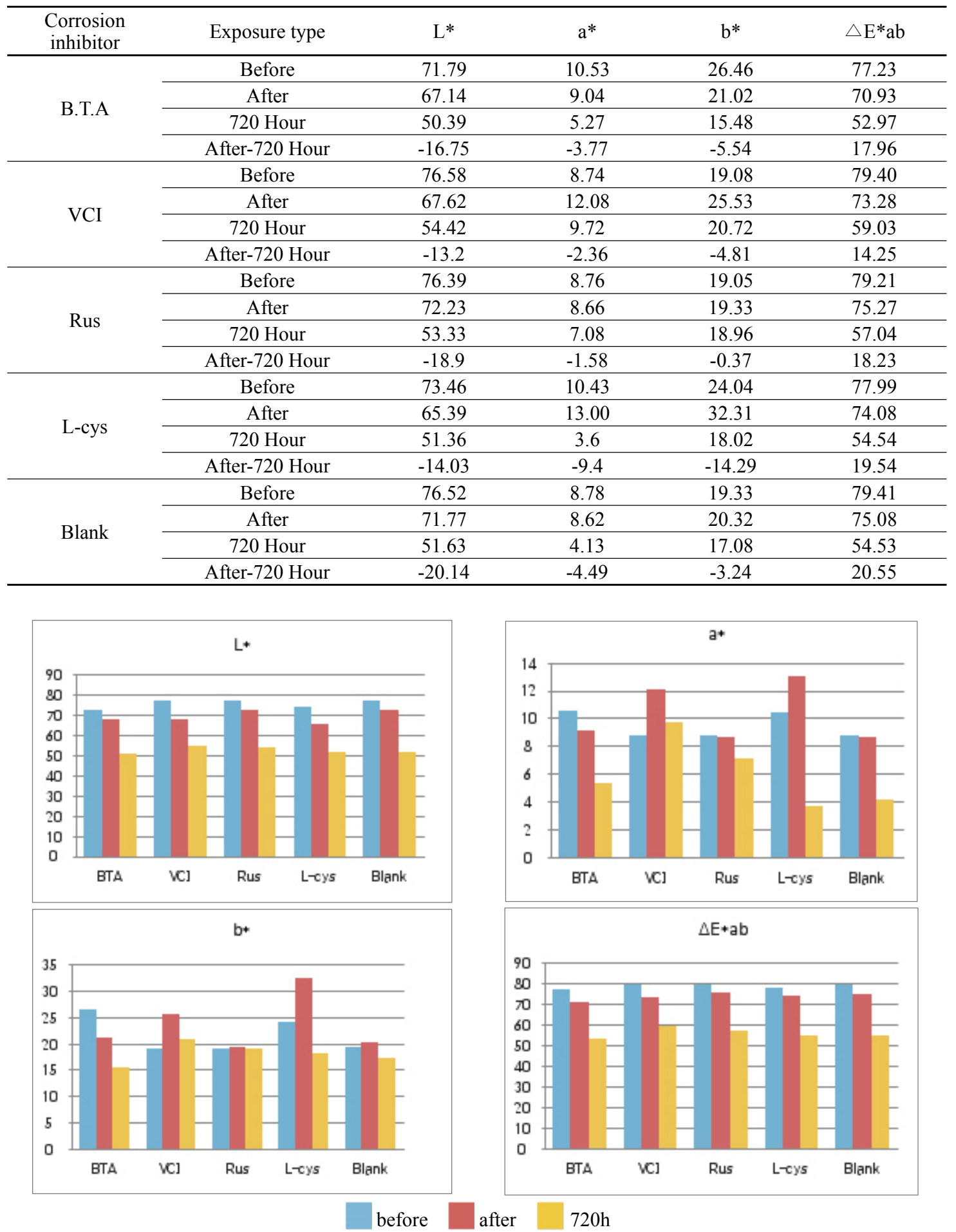

Figure 5. Color-difference value of outdoor environment exposure. 
environment for 720 hours, Blank was -114.56 , which was changed the most greatly, and VCI was -28.19 , which could obtain the smallest change value. It was verified that the gloss change became bigger in the order of Blank $>$ L-cys $>$ B.T.A $>$ Rus $>$ VCI, and accordingly, it was considered that VCI had better corrosion inhibition effects in the outdoor atmospheric environment(Figure 6).

\subsection{Measurement methods}

\subsubsection{Measuring the contact angle}

As a result of measuring the contact angle, the mean values for respective corrosion inhibitors were $68.76^{\circ}$, $19.58^{\circ}, 78.05^{\circ}, 72.49^{\circ}$ and $81.72^{\circ}$ for B.T.A, VCI, Rus, L-cys and Blank, respectively, and the mean value of contact angle was represented bigger in the order of Blank $>$ Rus $>$ L-cys $>$ B.T.A $>$ VCI. Unlike the test pieces treated by the corrosion inhibitor, the contact angle of the Blank test piece showed the greatest value, so it was considered that corrosion inhibitors had the high resistance to water. In particular, VCI was considered to be so high hydrophilic that was easy to combine with water because its contact angle showed the smallest value. However, its corrosion inhibition effect could be verified through other material property test, so if the water-soluble corrosion inhibitor's weakness of being washed away by water could be complemented through surface coating after corrosion inhibition treatment, it was considered to get corrosion inhibition effects effectively when applying to outdoor copper alloy(Table 13).

\subsubsection{GC analysis and MSDS data}

As a result of the GC analysis, it was verified that the chemicals analyzed in B.T.A, Rus and L-cys could be somewhat harmful based on the MSDS data. In VCI,

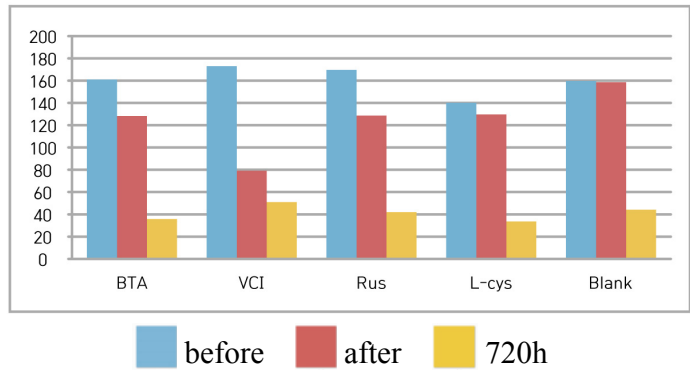

Figure 6. Gloss measurement of outdoor environment exposure.

Table 12. Gloss measurement of outdoor environment exposure

\begin{tabular}{cccccc}
\hline \multirow{2}{*}{ Exposure type } & \multicolumn{5}{c}{ Corrosion inhibitor } \\
\cline { 2 - 6 } & B.T.A & VCI & Rus & L-cys & Blank \\
\hline Before & 161 & 173 & 169.6 & 140.1 & 159.7 \\
\hline After & 128.3 & 79.05 & 128.6 & 129.7 & 158.6 \\
\hline 720 Hour & 35.75 & 50.86 & 41.89 & 33.49 & 44.04 \\
\hline After-720 Hour & -92.55 & -28.19 & -86.71 & -96.21 & -114.56 \\
\hline
\end{tabular}

Table 13. Contact angle of corrosion inhibitor

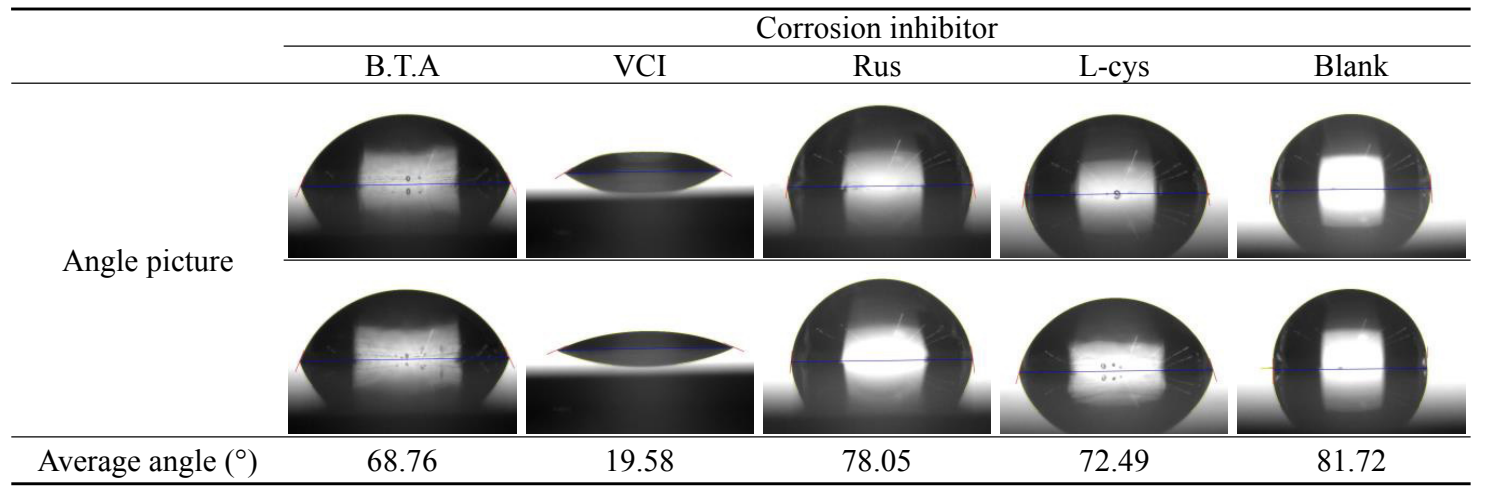


Table 14. Gas chromatographic analysis and MSDS data of corrosion inhibitor

\begin{tabular}{|c|c|c|c|c|}
\hline Results & B.T.A & VCI & Rus & L-cys \\
\hline $\mathrm{Pk} \#$ & 2 & 7 & 11 & 18 \\
\hline RT & 12.862 & 10.787 & 15.960 & 14.595 \\
\hline Area (\%) & 67.82 & 33.75 & 28.99 & 10.07 \\
\hline Library & Benzoxazole & Octanoic acid & 1-(Epoxymethano)-7 & 7-Amino-1 \\
\hline MSDS & $\begin{array}{c}\text { H302: Harmful if } \\
\text { swallowed } \\
\text { H319: Causes serious } \\
\text { eye irritation. } \\
\text { H332: Harmful if } \\
\text { inhaled. } \\
\text { H335: May cause } \\
\text { respiratory irritation }\end{array}$ & (No data) & $\begin{array}{l}\text { H373: May cause } \\
\text { damage to organs } \\
\text { through prolonged or } \\
\text { repeated exposure. }\end{array}$ & $\begin{array}{c}\text { H302 : Harmful if } \\
\text { swallowed } \\
\text { H319: Causes severe eye } \\
\text { irritation }\end{array}$ \\
\hline
\end{tabular}

however, the octanic acid contained in plant bodies was detected, and a result of having low harmfulness and risk to humans could be drawn because there was no data on its harmfulness in the MSDS data(Table 14).

\section{CONCLUSION AND DISCUSSION}

This study had selected the water-soluble corrosion inhibitor, which was easier to use than the existing wax and B.T.A being used in corrosion inhibition treatment for outdoor copper alloy, to conduct the material property measurement and scientific analysis methods of applying environmental experiments for applicability to the copper alloy exposed to outdoor environments, and drawn the following conclusion.

First, as a result of applying environmental experiments to measure the material property of corrosion inhibitors, L-cys showed the smallest color change before and after applying the corrosion inhibitors. However, as a result of conducting environmental experiments such as salt spray, acid corrosion and outdoor exposure tests, it showed the greatest color change value, and unlike other corrosion inhibitors, it had an echo-friendly structure of amino acid components, which was less harmful, but showed low result values in terms of weather resistance, so it was verified to be unsuitable for applicability. On the contrary, VCI had great color changes before and after applying corrosion inhibitors, but showed the smallest color change values after the environmental experiments, so it was considered to have better effects on weather resistance to be very applicable to the corrosion inhibitor for outdoor copper alloy.

Second, as a result of measuring contact angles among scientific analysis methods, Blank test pieces showed the greatest contact angle, and the test pieces, in which corrosion inhibitors were applied, showed relatively small contact angles. According to such a result, it could be verified that the corrosion inhibitors had low resistance to water because they were produced as water soluble to increase their penetrability, and it could be also verified through the test pieces in which stains were observed since some of the corrosion inhibitor was dissolved in the water during the salt spray and outdoor exposure tests. Therefore, it was considered to obtain better corrosion inhibition effects of water-soluble corrosion inhibitors if surface coating was conducted after treatment to increase their resistance to water for improvement of their effects when actually applying to 
outdoor copper alloy.

B.T.A, Rus and L-cys were likely to be harmful to humans because the data on their harmfulness and risk could be verified on the basis of the GC analysis result and MSDS data, but VCI was considered to be an eco-friendly corrosion inhibitor being harmless to humans because only the preservative component was detected but dangerous material was not found.

Based on such a result, it could reach the conclusion that the material showing the best weather resistance among corrosion inhibitors for outdoor copper alloy is VCI which is a water-soluble corrosion inhibitor for copper alloy, and it could be considered to be applied in replacement of B.T.A due to its low harmfulness. In addition, VCI is judged to serve as a corrosion inhibitor for outdoor copper alloy because it showed the best result even in the outdoor exposure test which is a real atmospheric environment.

\section{REFERENCES}

Chun, Y.J., Park, Y.S. and Soh, S.Y., 1999, Synthesis and performance of dialkylamine (di-)nitrobenzoates for vapor corrosion inhibitor. Applied Chemistry for Engineering, 10(1), 6-11. (in Korean with English abstract)

Fontana, M.G., 1986, Corrosion engineering. McGraw-Hill, New York, 3, 172.

Kim, B.H., 2012, An effect of corrosion inhibitors on iron artifacts. Master's thesis, Myongji University, Seoul, 30. (in Korean with English abstract)

Kim, H.S., 2010, A study on corrosion inhibitors used in conservation for iron artifact. Master's thesis, Yong-in University, Yong-in, 13-14. (in Korean with English abstract)

Kwon, H.H., Kim, Y.S., Kim, B.J., Choi, N.Y., Park, H.S. and Kim, J.S., 2017, A study on conservation and material characteristics of outdoor bronze sculpture : Kim Chan Shik's 'Feeling'. Journal of Conservation Science, 33(3), 155-165. (in Korean with English abstract)

Seo, J.h., 2008, Conservation methodology for cultural properties. Kyungin Publishing, Paju, 38. (in Korean with English abstract)

Woo, D.R., 2013, Comparison of the capability of corrosion inhibitors to conserve of bronze artifacts. Master's thesis, Chung-buk University, Cheongju, 18. (in Korean with English abstract) 